\section{Health Promotion Programs Not Easily Categorized}

Dear Editor:

The article by Gore and Kotari in the January/February issue of the Canadian Journal of Public Health ${ }^{1}$ highlighted the difference between environmental and structural approaches to improving health and reducing health inequities through an analysis of Farm to School health promotion initiatives. Unfortunately, the article implied that structural approaches (i.e., system level policy changes) are superior to environmental approaches (i.e., making healthy food available in selected school settings) and left the impression that the two approaches are mutually exclusive.

Farm to School programs are intentionally designed to impact the school as an institution and to target structural elements of the food system. By intentionally linking the school's food purchasing to local producers, the approach encourages local economic development. ${ }^{2}$ By adopting a community development approach and involving parents and others, community engagement and social connectivity (a determinant of health) is also promoted. ${ }^{3}$ A wellfunctioning school system that incorporates and sustains parent involvement, especially low-income parents, is a key structural change that can have a significant impact on children's health. ${ }^{4}$

The effort to change both environmental and structural factors in a community is one of the strengths of the Farm to School approach and may be mutually reinforcing. Programs at the environmental level can set the stage for changes at the structural level. Experiences with tobacco regulation suggest that changes in social norms have an interactive relationship with policy change. ${ }^{5}$ In the case of Farm to School programs, awareness of food insecurity may increase advocacy to change the structures that perpetuate inequities in our society. Never underestimate the number of par- ents who become concerned when they learn that some of their children's playmates go to school hungry or are from families who have to manage on less than healthy diets. One job of public health is to bring these inequities to light and create opportunities for dialogue to address them as well as build momentum for structural change. ${ }^{6}$

While the authors have made a needed case for structural interventions, the benefits of the Farm to School approach need to be evaluated against a range of potential outcomes and not just the access to healthy food for students involved in the program. The practice of population health work is messy and interventions are not bounded by conceptual maps.

Ted Bruce, MA, Past President, Public Health Association of British Columbia

\section{REFERENCES}

1. Gore DM, Kothari AR. Getting to the root of the problem: Health promotion strategies to address the social determinants of health. Can J Public Health 2013;104(1):e52-e54.

2. Stott D, Nichols E. Research into Local Food Within School Districts Across North America. Prepared for the Public Health Association of BC and the Greater Vancouver Farm to School Steering Committee. March 8, 2013.

3. BC Healthy Living Alliance. Semi-Annual Progress Report - Farm to School Initiative. February 16, 2009.

4. Pivik J. Environmental Scan of School Readiness for Health. National Collaborating Centre for Determinants of Health. March 2012. Available at: http://nccdh.ca/resources/entry/environmental-scan-of-school-readiness-forhealth (Accessed April 1, 2013).

5. Robert Wood Johnson Foundation. Social Norms and Attitudes About Smoking. April 2011. Available at: http://www.rwjf.org/content/dam/webassets/2011/04/social-norms-and-attitudes-about-smoking (Accessed April 1, 2013).

6. Sudbury and District Health Unit. 10 Promising Practices to Guide Local Public Health Practice to Reduce Social Inequities in Health: Technical Briefing. Sudbury, ON, 2011. 